\title{
High Endemicity with Clonorchis sinensis Metacercariae in Fish from Yongjeon-cheon (Stream) in Cheongsong-gun, Gyeongsangbuk-do, Korea
}

\author{
Woon-Mok Sohn ${ }^{1, *} \mathbb{E}$, Byoung-Kuk Na ${ }^{1}$, Shin-Hyeong $\mathrm{Cho}^{2}$, Hee II Lee², Myoung-Ro Lee², Jung-Won Ju², \\ Gou Ok Kim ${ }^{3}$ \\ ${ }^{1}$ Department of Parasitology and Tropical Medicine, and Institute of Health Sciences, Gyeongsang National University College of Medicine, Jinju \\ 52727, Korea; '2Division of Vectors and Parasitic Diseases, Korea Disease Control and Prevention Agency, Osong 28159, Korea; ${ }^{3}$ Infectious Disease \\ Research Division, Gyeongsangbuk-do Government Public Institue of Health and Environment, Yeongcheon 38874, Korea
}

\begin{abstract}
The infection status with Clonorchis sinensis metacercariae (CsMc) was examined in freshwater fishes from Yongjeon-cheon (a branch of Nakdong-gang) located in Cheongsong-gun, Gyeongsangbuk-do, the Republic of Korea (Korea). A total of 750 fishes in 19 species were examined by the artificial digestion method for 2 years (2019 and 2020 ). CsMc were detected in 378 (51.4\%) out of 735 fishes in 14 species (73.7\%), and the infection intensity was 666 per fish infected. In 2019, CsMc were found in 172 (68.0\%) out of 253 fishes in 10 species, and the infection intensity was 565 per fish infected. In 2020, CsMc were detected in 206 (62.2\%) out of 331 fishes in 10 species, and the infection intensity was 751 per fish infected. The other zoonotic trematode, ie. Metagonimus spp., Centrocestus armatus, Echinostoma spp. and Clinostomum complanatum, metacercariae were also detected in fishes from the survey streams, but their endemicities were relatively low. Conclusively, it was first confirmed that CsMc are highly endemic in fishes from Yongjeon-cheon in Cheongsong-gun, Gyeongsangbuk-do, Korea.
\end{abstract}

Key words: Clonorchis sinensis, Zoonotic trematode metacercaria, Cyprinidae fish host, Yongjeon-cheon, Cheongsong-gun, Korea

Nowadays, clonorchiasis, Clonorchis sinensis (Digenea: Opisthorchiidae) infection, is most important as an endemic parasitic disease in the Republic of Korea (Korea) [1]. The prevalence of clonorchiasis has maintained at relatively high levels in the residents of riverside areas in Korea. A team of Korea DCPA (Division of Vectors and Parasitic Diseases, Korea Disease Control and Prevention Agency) has performed the control programs to decrease the prevalence of clonorchiasis in the residents of major river basins in Korea [2-6]. On the other hand, co-working groups of Korea DCPA have epidemiologically surveyed the freshwater fishes, the infection sources, to estimate the endemicities of clonorchiasis [6-11]. Especially, Cho et al. [6] investigated the infection status of CsMc in freshwater fish from various regions of Korean peninsula. Sohn et al. [8] and Yoon et al. [9] investigated the infection status of CsMc in freshwater fishes from the water systems of Seomjin-

\footnotetext{
- Received 14 December 2020, revised 21 January 2021, accepted 21 January 2021.

*Corresponding author (wmsohn@gnu.ac.kr)

(C) 2021, Korean Society for Parasitology and Tropical Medicine

This is an Open Access article distributed under the terms of the Creative Commons Attribution Non-Commercial License (https://creativecommons.org/licenses/by-nc/4.0) which permits unrestricted non-commercial use, distribution, and reproduction in any medium, provided the original work is properly cited.
}

gang and Tamjin-gang. Recently, Sohn et al. [10,11] also surveyed the infection status of CsMc in freshwater fish from 2 highly endemic areas, Wi-cheon (cheon means stream) and Yangcheon (branch streams of Nakdong-gang), in Gunwi-gun (gun= county), Gyeongsangbuk-do and Sancheong-gun, Gyeongsangnam-do, Korea.

Yongjeon-cheon is one of the branch stream of Nakdong-gang, which rise from a mountinous area (Guam-san) (san means mountain) of Bunam-myeon (myeon=township), flows via Juwangsan-myeon and Cheongsong-eup (eup=town) unites with Banbyeon-cheon in Pacheon-myeon, Cheongsong-gun, Gyeongsangbuk-do. This stream flows only in Cheongsong-gun areas as the most big stream in Cheongsong-gun [12]. A riverside area of Yongjeon-cheon was reported as a high endemic area of echinostomiasis [13]. However, the infection status with zoonotic trematode metacercariae (ZTM) including CsMc in fish from this area has not been widely and systematically examined yet. Therefore, we intended to investigate the infection status with CsMc in fishes from Yongjeon-cheon for 2 years, 2019 and 2020.

We collected a total of 750 freshwater fishes in 19 species in 2 sites, midstream (Cheongwoon-ri in Cheongsong-eup: 36. 
39995; 129.07015), and downstream (Gwan-ri in Pacheon-myeon: 36.44223; 129.03083), of Yongjeon-cheon (a branch stream of Nakdong-gang), which is located in Cheongsonggun, Gyeongsangbuk-do, Korea for 2 years (2019 and 2020). In the midstream, a total of 382 freshwater fish in 12 species were examined, and the fish species (No. of fish) examined were as follows: Pungtungia herzi (132), Zacco platypus (77), Zacco koreanus (54), Coreoperca herzi (40), Acheilognathus koreensis (34), Odontobutis platycephala (22), Carassius auratus (11), Coreoleuciscus splendidus (6), Opsariichthys uncirostris (2), Siniperca scherzeri (2), Squalidus gracilis majimae (1), Pseudogobio esocinus (1). Total 368 freshwater fish in 18 species from downstream were examined, and the fish species (No. of fish) examined were as follows: P. herzi (102), A. koreensis (60), Z. koreanus (44), Z. platypus (40), Acanthorhodeus macropterus (33), C. herzi (26), Acheilognathus lanceolatus (20), O. platycephala (19), C. auratus (6), Micropterus salmoides (6), P. esocinus (4), O. uncirostris (1), S. gracilis majimae (2), Acheilognathus majusculus (1), Hemibarbus longirostris (1), Hemibarbus labeo (1), Acheilognathus rhombeus (1), S. scherzeri (1).

All collected fishes were transferred to the laboratory of the Department of Parasitology and Tropical Medicine, Gyeongsang National University College of Medicine, Jinju, Korea. After the identification of fish species [14], they were individual- ly examined by the artificial digestion method $[15,16]$. Collected CsMc were counted to get hold of prevalences (No. of fish with $\mathrm{CsMc} /$ No. of fish examined $\times 100$ ) and infection intensities (No. of CsMc/a fish infected) by fish species.

The metacercariae of $C$. sinensis (CsMc) were detected in 378 (51.4\%) out of 735 fishes in 14 species (73.7\%), and the infection intensity was 666 per fish infected. The infection status by the fish species and fish group (subfamilies in Cyprinidae) was shown in Table 1. In 2019, CsMc were detected in 172 (68.0\%) out of 253 fishes in 10 species, and the infection intensity was 565 per fish infected. The infection status by the fish species and survey site was detailedly revealed in Table 2 . In 2020, CsMc were detected in 206 (62.2\%) out of 331 fishes in 10 species, and the infection intensity was 751 per fish infected. The infection status by the fish species and survey site was designated in Table 3 in detail.

Metagonimus spp. metacercariae were found in 304 (42.9\%) out of 708 fishes in 11 species (57.9\%), and the infection intensity was 14.6 per fish infected. The metacercariae of Centrocestus armatus were detected in 167 (38.7\%) out of 431 fishes in 7 species (36.8\%), and the infection intensity was 615 per fish infected. Echinostoma spp. metacercariae were found in 310 (42.3\%) out of 733 fishes in 13 species (68.4\%), and the infection intensity was 29.6 per fish infected. The metacercariae

Table 1. Overall infection status of Clonorchis sinensis metacercariae by the fish species from Yongjeon-cheon in Cheongsong-gun, Gyeongsangbuk-do, Korea

\begin{tabular}{|c|c|c|c|c|}
\hline \multirow{2}{*}{ Species of fish } & \multirow{2}{*}{ No. of fish examined } & \multirow{2}{*}{ No. (\%) of fish infected } & \multicolumn{2}{|c|}{ No. of CsMc detected } \\
\hline & & & Range & Average \\
\hline Pungtungia herzi & 234 & $226(96.6)$ & $1-21,510$ & 1,098 \\
\hline Squalidus gracilis majimae & 3 & $2(66.7)$ & $31-1,340$ & 686 \\
\hline Subtotal & 237 & 228 (96.2) & $1-21,510$ & 1,094 \\
\hline Acheilognathus koreensis & 94 & $70(74.5)$ & $1-154$ & 11.1 \\
\hline Acheilognathus lanceolatus & 20 & $7(35.0)$ & $1-357$ & 125 \\
\hline Acheilognathus majusculus & 1 & $1(100)$ & - & 176 \\
\hline Subtotal & 148 & $96(64.9)$ & $1-357$ & 20.1 \\
\hline Zacco platypus & 117 & $38(32.5)$ & $1-109$ & 11.8 \\
\hline Zacco koreanus & 98 & $1(1.0)$ & - & 1.0 \\
\hline Opsarriichthys uncirostris & 3 & $3(100)$ & $1-21$ & 10.0 \\
\hline Coreoperca herzi & 66 & $2(3.0)$ & - & 1.0 \\
\hline Odontobutis platycephala & 41 & $2(4.9)$ & $1-3$ & 2.0 \\
\hline Carassius auratus & 17 & $1(5.9)$ & - & 1.0 \\
\hline Pseudogobio esocinus & 5 & $5(100)$ & $1-18$ & 10.4 \\
\hline Siniperca scherzeri & 3 & $2(66.7)$ & $1-3$ & 2.0 \\
\hline Subtotal & 132 & $12(9.1)$ & $1-18$ & 5.3 \\
\hline Total & 735 & $378(51.4)$ & $1-21,510$ & 666 \\
\hline
\end{tabular}


of Clinostomum complanatum were detected in 85 (15.1\%) out of 564 fishes in 6 species (31.6\%), and the infection intensity was 3.2 per fish infected (Table 4).
By the present study, it was confirmed for the first time that CsMc are highly endemic in fishes from Yongjeon-cheon, in Cheongsong-gun, Gyeongsangbuk-do, Korea. The infection

Table 2. Infection status of Clonorchis sinensis metacercariae in fishes from Yongjeon-cheon in Cheongsong-gun, Gyeongsangbuk-do (2019)

\begin{tabular}{|c|c|c|c|c|}
\hline \multirow{2}{*}{ Locality and fish sp. examined } & \multirow{2}{*}{ No. of fish examined } & \multirow{2}{*}{ No. (\%) of fish infected } & \multicolumn{2}{|c|}{ No. of CsMc detected } \\
\hline & & & Range & Average \\
\hline \multicolumn{5}{|l|}{ Midstream } \\
\hline Pungtungia herzi & 62 & $55(88.7)$ & $1-11,580$ & 787 \\
\hline Zacco platypus & 42 & $19(45.2)$ & $1-109$ & 14.6 \\
\hline Coreoperca herzi & 24 & $2(8.3)$ & - & 1.0 \\
\hline Carassius auratus & 9 & $1(11.1)$ & - & 1.0 \\
\hline Acheilognathus koreensis & 8 & $3(37.5)$ & $1-13$ & 5.0 \\
\hline Opsarriichthys uncirostris & 2 & $2(100)$ & $8-21$ & 14.5 \\
\hline Subtotal & 147 & $82(55.8)$ & $1-11,580$ & 532 \\
\hline \multicolumn{5}{|l|}{ Downstream } \\
\hline Pungtungia herzi & 39 & $39(100)$ & $14-6,950$ & 1,301 \\
\hline Acheilognathus koreensis & 20 & $19(95.0)$ & $1-154$ & 13.1 \\
\hline Acanthorhodeus macropterus & 20 & $11(55.0)$ & $1-11$ & 2.6 \\
\hline Zacco platypus & 19 & $13(68.4)$ & $1-86$ & 12.3 \\
\hline Acheilognathus lanceolatus & 5 & $5(100)$ & $13-357$ & 174 \\
\hline Squalidus gracilis majimae & 1 & $1(100)$ & - & 1,340 \\
\hline Acheilognathus majusculus & 1 & $1(100)$ & - & 176 \\
\hline Opsarriichthys uncirostris & 1 & $1(100)$ & - & 1.0 \\
\hline Subtotal & 106 & $90(84.9)$ & $1-6,950$ & 595 \\
\hline Total & 253 & $172(68.0)$ & $1-11,580$ & 565 \\
\hline
\end{tabular}

Table 3. Infection status of Clonorchis sinensis metacercariae in fishes from Yongjeon-cheon in Cheongsong-gun, Gyeongsangbuk-do (2020)

\begin{tabular}{|c|c|c|c|c|}
\hline \multirow{2}{*}{ Locality and fish sp. examined } & \multirow{2}{*}{ No. of fish examined } & \multirow{2}{*}{ No. (\%) of fish infected } & \multicolumn{2}{|c|}{ No. of CsMc detected } \\
\hline & & & Range & Average \\
\hline \multicolumn{5}{|l|}{ Midstream } \\
\hline Pungtungia herzi & 70 & $70(100)$ & $3-21,510$ & 1,759 \\
\hline Zacco platypus & 35 & $4(11.4)$ & $1-8$ & 2.8 \\
\hline Acheilognathus koreensis & 26 & $12(46.2)$ & $1-103$ & 23.6 \\
\hline Zacco koreanus & 26 & $1(3.9)$ & - & 1.0 \\
\hline Siniperca scherzeri & 2 & $1(50.0)$ & - & 1.0 \\
\hline Pseudogobio esocinus & 1 & $1(100)$ & - & 5.0 \\
\hline Subtotal & 160 & $89(55.6)$ & $1-21,510$ & 1,387 \\
\hline \multicolumn{5}{|l|}{ Downstream } \\
\hline Pungtungia herzi & 63 & $62(98.4)$ & $2-5,250$ & 498 \\
\hline Acheilognathus koreensis & 40 & $36(90.0)$ & $1-26$ & 6.3 \\
\hline Zacco platypus & 21 & $2(9.5)$ & - & 1.0 \\
\hline Acheilognathus lanceolatus & 15 & $2(13.3)$ & - & 1.0 \\
\hline Odontobutis platycephala & 13 & $2(15.4)$ & $1-3$ & 2.0 \\
\hline Acanthorhodeus macropterus & 13 & 7 (53.9) & $1-52$ & 11.3 \\
\hline Pseudogobio esocinus & 4 & $4(100)$ & $5-18$ & 11.8 \\
\hline Squalidus gracilis majimae & 1 & $1(100)$ & - & 31.0 \\
\hline Siniperca scherzeri & 1 & $1(100)$ & - & 3.0 \\
\hline Subtotal & 171 & $117(68.4)$ & $1-5,250$ & 267 \\
\hline Total & 331 & $206(62.2)$ & $1-21,510$ & 751 \\
\hline
\end{tabular}


Table 4. Overall infection status with other zoonotic trematode metacercariae (ZTM) in fishes ${ }^{a}$ from Yongjeon-cheon in Cheongsonggun, Gyeongsangbuk-do, Korea

\begin{tabular}{lccccc}
\hline Species of fish & $\begin{array}{c}\text { Positive No. (\%) } \\
\text { of fish sp. }\end{array}$ & $\begin{array}{c}\text { No. of fish } \\
\text { examined }\end{array}$ & $\begin{array}{c}\text { No. (\%) of fish } \\
\text { infected }\end{array}$ & \multicolumn{2}{c}{ No. of ZTM detected } \\
\cline { 5 - 6 } Metagonimus spp. & $11(57.9)$ & 708 & $304(42.9)$ & $1-200$ & Range \\
Centrocestus armatus & $7(36.8)$ & 431 & $167(38.7)$ & $1-3,101$ & 14.6 \\
Echinostoma spp. & $13(68.4)$ & 733 & $310(42.3)$ & $1-767$ & 29.6 \\
Clinostomum complanatum & $6(31.6)$ & 564 & $85(15.1)$ & $1-20$ & 3.2 \\
\hline
\end{tabular}

${ }^{\text {aA }}$ total of 750 fishes in 19 species were examined.

status was revealed with a certain tendency by the subfamily groups, i.e., Gobioninae, Acheilognathinae and Rasborinae, in the cyprinid fish (family Cyprinidae) hosts of $C$. sinensis like in Sohn et al. [10,11]. The prevalences of CsMc were 96.2\%, $64.9 \%$ and $19.3 \%$, and infection intensities with CsMc were $1,094,20$ and 11 per fish infected in 3 fish groups respectively. In this study, prevalences and infection intensities are somewhat lower than those in fish from Wi-cheon [10], but much higher than those in fish from Yang-cheon [11]. And then, we can also know that the endemicity of CsMc is closely related with the subfamily groups, i.e., Gobioninae, Acheilognathinae and Rasborinae, in the cyprinid fish hosts from a highly endemic area, Yongjeon-cheon, in Cheongsong-gun, Gyeongsangbuk-do, Korea.

The ecological conditions for fish was not so good in Yongjeoncheon. Total 750 freshwater fishes in 19 species were collected in 2 survey sites of Yongjeon-cheon in this study. Among them, striped shinner (P. herzi: 31.2\%), was the most dominant fish species like in Tamjin-gang [9] and Wi-cheon [10] and in Yangcheon [11], and followed by pale chub (Z. platypus: 15.6\%), Korean chub (Z. koreanus: 13.1\%), oily bitterling (A. koreensis: $12.5 \%)$, Korean aucha perch (C. herzi: 8.8\%), Korean dark sleeper (O. platycephala: 5.5\%), deep body bitterling (A. macropterus: $4.4 \%$ ), slender bitterling (A. lanceolatus: $2.7 \%$ ) and crusian carp (C. auratus: 2.3\%). The number of fish examined was $720(96.0 \%)$ in major 9 species and $30(4.0 \%)$ in remain 10 species. The disproportion of fish number and a small number of fish species examined is suggested that the ecological condition for fish was relatively not so good.

Edible fish species in raw, i.e., Korean aucha perch (C. herzi), Korean dark sleeper (O. platycephala), crusian carp (C. auratus) and Mandarin fish (S. scherzeri), practically act as the infection sources of clonorchiasis in Korea. Fortunately, these fish species are less prevalent with CsMc like in such a highly endemic area, Wicheon [10]. In this study, 2 (3.0\%) out of 66 C. herzi were infected with 2 CsMc, 2 (4.9\%) of 41 O. platycephala were infected with total 4 CsMc, only 1 (5.9\%) out of 17 C. auratus were retained with 1 CsMc and 2 (66.7\%) S. scherzeri were infected with a total of $4 \mathrm{CsMc}$. CsMc were not detected at all in 4 fish species, i.e., C. herzi $(\mathrm{n}=57)$, C. auratus (42), S. scherzeri (11) and C. carpio (2), from the water systems of Seomjin-gang [8]. Only one CsMc were found in only $1(1.1 \%)$ out of $93 \mathrm{C}$. herzi and no CsMc were detected from 73 C. auratus, 36 O. platycephala and 1 S. scherzeri from Yang-cheon in Sancheonggun, Gyeongsangnam-do, Korea [11].

The striped shinner, $P$. herzi, is regarded as the index fish species of CsMc infection, so this fish species is broadly live in the water systems of Korea and is highly susceptibe with CsMc. The proportion of this fish species examined were $12.3 \%$ in Seomjin-gang [8], 13.5\% in Tamjin-gang [9], 14.5\% in Wicheon [10], 24.3\% in Yang-cheon [11] and 31.2\% in this study. In this study, total 226 (96.6\%) P. herzi were infected with 1,098 CsMc in average. Therefore, the endemicity (susceptibility index $=$ prevalence $/ 100 \times$ No. of CsMc in average) was $1,060.7$. This value is somewhat lower than that $(1,550)$ in Wi-cheon [10]. However, it is higher than those in Seomjingang (34.8) [8], Tamjin-gang (103.2) [9] and Yang-cheon (146.4) [11]. Accordingly, based on the susceptibility index of CsMc in the index fish, P. herzi, we can know that Wi-cheon and Yongjeon-cheon are highly endemic, Yang-cheon and Tamjin-gang are moderately endemic, and Seomjin-gang is more or less low endemic areas.

Conclusively, it is confirmed for the first time that CsMc is highly endemic in fishes, especially in P. herzi, from Yongjeoncheon and the infection tendency of CsMc is obviously showed by 3 subfamily groups, i.e., Gobioninae, Acheilognathinae and Rasborinae, in the family Cyprinidae fish hosts from Yongjeoncheon in Cheongsong-gun, Gyeongsangbuk-do, Korea.

\section{ACKNOWLEDGMENTS}

This study was supported by an anti-communicable diseases 
control program, 2019 and 2020 (Investigation and analysis on the infections of zoonotic trematode metacercariae in fish intermediate hosts in the Republic of Korea) of Division of Vectors and Parasitic Diseases, Korea Centers for Disease Control and Prevention (KCDCP). This work was partly supported by the Gyeongsang National University Fund for Professors on Sabbatical Leave, 2020. We thank Jung-A Kim, Hee-Joo Kim and You-Jin Ryu (Department of Parasitology and Tropical Medicine, Gyeongsang National University College of Medicine, Jinju, Korea), for their help in the examination of fish.

\section{CONFLICT OF INTEREST}

The authors have no conflicts of interest concerning the work reported in this paper.

\section{REFERENCES}

1. Korea Centers for Disease Control and Prevention, Korea National Institute of Health. National Survey of the Prevalence of Intestinal Parasitic Infections in Korea, 2012. The 8th Report. Osong, Korea. Korea Centers for Disease Control and Prevention. 2013.

2. Cho SH, Lee KY, Lee BC, Cho PY, Cheun HI, Hong ST, Sohn WM, Kim TS. Prevalence of clonorchiasis in southern endemic areas of Korea in 2006. Korean J Parasitol 2008; 46: 133-137. https://doi.org/10.3347/kjp.2008.46.3.133

3. Kim HK, Cheun HI, Chung BS, Lee KY, Kim TS, Lee SE, Lee WJ, Cho SH. Prevalence of Clonorchis sinensis infections along the five major rivers in Republic of Korea, 2007. Osong Public Health Res Perspect 2010; 1: 43-49. https://doi.org/10.1016/ j.phrp.2010.12.010

4. June KJ, Cho SH, Lee WJ, Kim C, Park KS. Prevalence and risk factors of clonorchiasis among the populations served by primary healthcare posts along five major rivers in South Korea. Osong Public Health Res Perspect 2013; 4: 21-26. https://doi.org/10.1016/ j.phrp.2012.12.002

5. Jeong YI, Shin HE, Lee SE, Cheun HI, Ju JW, Kim JY, Park MY, Cho $\mathrm{SH}$. Prevalence of Clonorchis sinensis infection among residents along 5 major rivers in the Republic of Korea. Korean J Parasitol 2016; 54: 215-219. https://doi.org/ 10.3347/kjp.2016.54.2.215
6. Cho SH, Sohn WM, Na BK, Kim TS, Kong Y, Eom K, Seok WS, Lee T. Prevalence of Clonorchis sinensis metacercariae in freshwater fish from three latitudinal regions of the Korean Peninsula. Korean J Parasitol 2011; 49: 385-398. https://doi. org/10.3347/kjp.2011.49.4.385

7. Cho SH, Lee WJ, Kim TS, Seok WS, Lee TJ, Jeong KJ, Na BK, Sohn WM. Prevalence of zoonotic trematode metacercariae in freshwater fish from Gangwon-do, Korea. Korean J Parasitol 2014; 52: 399-412. https://doi.org/10.3347/kjp. 2014.52.4.399

8. Sohn WM, Na BK, Cho SH, Park MY, Kim CH, Hwang MA, No KW, Yoon KB, Lim HC. Prevalence of Clonorchis sinensis metacercariae in fish from water systems of Seomjin-gang (River). Korean J Parasitol 2017; 55: 305-312. https://doi.org/10.3347/kjp. 2017.55.3.305

9. Yoon KB, Lim HC, Jeon DY, Park S, Cho SH, Ju JW, Shin SS, Na BK, Sohn WM. Infection status with Clonorchis sinensis metacercariae in fish from Tamjin-gang (River) in Jeollanam-do, Republic of Korea. Korean J Parasitol 2018; 56: 183-188. https://doi. org/10.3347/kjp.2018.56.2.183

10. Sohn WM, Na BK, Cho SH, Ju JW, Son DC. Prevalence and intensity of Clonorchis sinensis metacercariae in freshwater fish from Wi-cheon stream in Gunwi-gun, Gyeongsangbuk-do, Korea. Korean J Parasitol 2018; 56: 41-48. https://doi.org/ 10.3347/kjp.2018. 56.1 .41

11. Sohn WM, Na BK, Cho SH, Ju JW. Infection status with Clonorchis sinensis metacercariae in fish from Yang-cheon (Stream) in Sancheong-gun, Gyeongsangnam-do, Korea. Korean J Parasitol 2019; 57: 145-152. https://doi.org/10.3347/kjp. 2019.57.2.145

12. Yongjeon-cheon in Cheongsong-gun, Gyeongsangbuk-do (South Korea) in Wikipedia-The free encyclopedia; http://ko.wikipedia org.

13. Lee SK, Chung NS, Ko IH, Sohn WM, Hong ST, Chai JY, Lee SH An epidemiological survey of Echinostoma hortense infection in Chongsong-gun, Kyongbuk province. Korean J Parasitol 1988; 26: 199-206 (in Korean). https://doi.org/10.3347/kjp.1988.26.3.199

14. Kim IS, Kang EJ. Coloured fishes of Korea. Seoul, Korea. Academy Publishing Company. 1993, pp 1-477 (in Korean).

15. Sohn WM. Fish-borne zoonotic trematode metacercariae in the Republic of Korea. Korean J Parasitol 2009; 47 (suppl): 103-113. https://doi.org/10.3347/kjp. 2009.47.S.S103

16. Sohn WM. Invertebrate Founa of Korea Vol. 6, No. 1. Trematodes. Incheon, Korea. The National Institute of Biological Resources. 2013, pp 1-125. 
